\title{
An accurate technique for supervising distance relays during power swing
}

\author{
Loai Mohamed Ali El-Sayed ${ }^{1}$, Doaa Khalil Ibrahim², Mahmoud Ibrahim Gilany ${ }^{3,}$ Aboul'Fotouh \\ El'Gharably ${ }^{4}$ \\ ${ }^{1,4}$ Electrical Power and Machines Department, Higher Institute of Engineering at El-Shorouk City, Egypt \\ ${ }^{2,3}$ Electrical Power Engineering Department, Faculty of Engineering, Cairo University, Egypt
}

\begin{tabular}{l} 
Article Info \\
\hline Article history: \\
Received Oct 20, 2020 \\
Revised Dec 20, 2020 \\
Accepted Jan 5, 2021 \\
\hline Keywords: \\
Phasor measurement unit \\
Power swing blocking \\
Power swing unblocking \\
Distance relay \\
Power system stability
\end{tabular}

Corresponding Author:

Loai Mohamed Ali El-Sayed

Electrical Power and Machines Department

The higher institute of engineering, Al-Shorouk City, Cairo, Egypt

Email: 1.mohamed.evergreen@gmail.com

\begin{abstract}
Power swing is a power system transient phenomenon that arises due to several reasons including line switching, line outage, sudden increment or decrement in load, faults, etc. Unnecessary tripping during power swing and unnecessary blocking for faults occur during power swing result in distance relay maloperation. Several cascaded outages and major worldwide blackouts have occurred due to maloperation of distance relays. This paper proposes a technique for supervising distance relays during power swing. The proposed online technique discriminates real faults and power swing accurately. It relies on constructing a locus diagram for the current and voltage differences $(\Delta \mathrm{I}-\Delta \mathrm{V})$ between the two ends of the protected line. The locus is estimated at every power frequency cycle to continuously monitor the state of the line by utilizing the synchrophasor measurements at the sending and receiving ends of the line. The proposed technique is tested for two-area, four-machine power system under faults at different locations of zone-1 and zone- 2 regions of distance relays, fault resistances, fault inception angles and slip frequencies using MATLAB software. The simulation results proved the superior improvement of distance relay performance for handling power swing blocking and unblocking actions.
\end{abstract}

This is an open access article under the $\underline{C C B Y-S A}$ license.

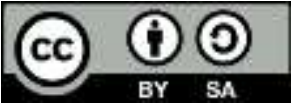

\section{INTRODUCTION}

Stability plays a vital role in ensuring the system reliability. In steady-state, the balanced power flow is maintained between the generation and load; nevertheless, the transient stability refers to the ability of synchronous generators to sustain their synchronism with power system following severe faults, unpredicted events or significant disruptions such as generator disconnection, line switching, or application of large loads. The equilibrium between generation and load can be disrupted by any of these events and thus the oscillation of electrical power occurs which known by power swing [1,2]. The fluctuations die down if the swing is stable, and the protective relays such as distance and overcurrent relays should be blocked [3, 4]. On the other hand, the disturbance can result in a condition in which the transient oscillations do not damp out and the system becomes unstable, commonly referred to as an out-of-step condition $[5,6]$.

The literature differentiates between faults and power swing based on the rate of change of some measured electrical parameters. The conventional techniques reported in [7] apply concentric circles and blinders to calculate the "rate of change of impedance" at relay location. However, these methods fail to 
differentiate the fault and fast swing conditions using local information. Power swing blocking (PSB) function based on swing center voltage (SCV) is also presented in [8], since SCV changes continuously during power swing and remains constant when a fault occurs. This criterion is used to differentiate faults and power swing, however, the main disadvantage, as presented in several literatures such as in [9], there is some delay in the detection due to fault inception when a three phase fault is initiated. Regarding signal analysis techniques, fast fourier transform (FFT) has been used to detect faults during power swing but appropriate selection of threshold values to fault detection is required [10]. The wavelet-based signal processing technique is also suggested in [11] for power swing identification, however high-frequency sampling is needed for implementation. The discrimination between high fault resistance and power swing is also examined in [12] for a test system interconnected with distributed generation (DG). Applying intelligence based diagnosis is also investigated in literature, where artificial intelligence techniques such as support vector machine and adaptive neuro-fuzzy inference system (ANFIS) are implemented in [13, 14]. Some significant problems for such approaches are discussed in [15], where the key deficiency is the enormous case studies needed for training.

As the world moves towards a smart grid, stability and reliability of the grid become the most challenging issues. Modern power systems depend on reliable communication infrastructure that supports data flow in real-time between devices and the control center. This is being realized as the time synchronized synchrophasor technology of global positioning system (GPS) in phasor measurement units (PMUs) opens up a cutting edge advancement in decision support and visualization algorithms inside a smart cyber power network [16]. In fact, PMUs are applied in different protection applications such as fault detection and backup schemes in [17, 18]. However, on a large scale complex grid, the primary protection idea is applied using the unique feature of phase plane fault identification in [19, 20]. A PMU based power swing detector is presented in [21] to prevent distance relay mal-operation. A differential power coefficient and angular separation are presented in [22] for fault detection and blocking/deblocking of distance relay.

The above literature shows that the available discrimination methods suffer from several problems that may limit their use and thus there is still a need for research studies to overcome such problems. Therefore, this paper proposes a novel online technique for dealing with power swing conditions using a unique index derived from the constructed $(\Delta I-\Delta V)$ locus for the sending and receiving ends current difference and voltage difference. The ellipse circumference of the locus is applied in an efficient logic scheme for blocking/unblocking distance relays to ensure accurate events detecting with minimal time delay.

The rest of the paper is arranged as follows: Section 2 describes the problem statement. Section 3 presents the methodology and description of the proposed technique. In Section 4, the test system is introduced. Section 5 describes the simulation tests and achieved results. Finally, the paper is eventually concluded in Section 6.

\section{PROBLEM STATEMENT}

The north american electric reliability corporation (NERC) has reported alarming statistics in [23], where $75 \%$ of the major disruptions that result in cascaded outages and major blackouts include distance relay maloperation. Some countries have experienced major blackouts due to distance relay nuisance tripping during power swing as the apparent impedance may fall within operating zones or blocking for faults occurring during power swing [24].

In fact, power swing is a balanced phenomenon, thus it is easy to distinguish unsymmetrical faults from power swing due to the existence of negative and/or zero sequence components of the current and voltage during such faults. On the contrary, it is very difficult to differentiate symmetrical faults from power swing especially the symmetrical faults that occur during power swings as both of them have a balanced nature [25]. Therefore, an online technique is proposed to discriminate real faults and power swing accurately. It relies on creating a locus diagram at every power frequency cycle to continuously identify the state of the line by using the synchrophasor measurements at the sending and receiving ends of the line. The data was obtained from $4 \mathrm{G}$ technology-based PMUs to provide high data speeds over long distance. Thus, the proposed technique is allowed in real-time to serve as a primary protection to differentiate correctly between faults and power swings. It is also capable of detecting symmetrical faults even with high fault resistances during power swing.

\section{THE PROPOSED TECHNIQUE}

The simple $60 \mathrm{~Hz}$ power system presented in Figure 1 shows how to synchronize data using GPS between two ends relays (R1 \& R2 for Line-1 and R3\& R4 for Line-2). PMUs are placed at bus M and bus $\mathrm{N}$ to gather local measurements. The extracted data of instantaneous voltages and current values from PMUs 
are collected at the PDC. The proposed technique uses synchronized measurements of instantaneous phase voltages and current values at bus $\mathrm{M}$ and bus $\mathrm{N}$ recorded for one complete cycle and sampled at $0.1 \mathrm{~ms}$ to plot the $(\Delta I-\Delta V)$ ellipse.

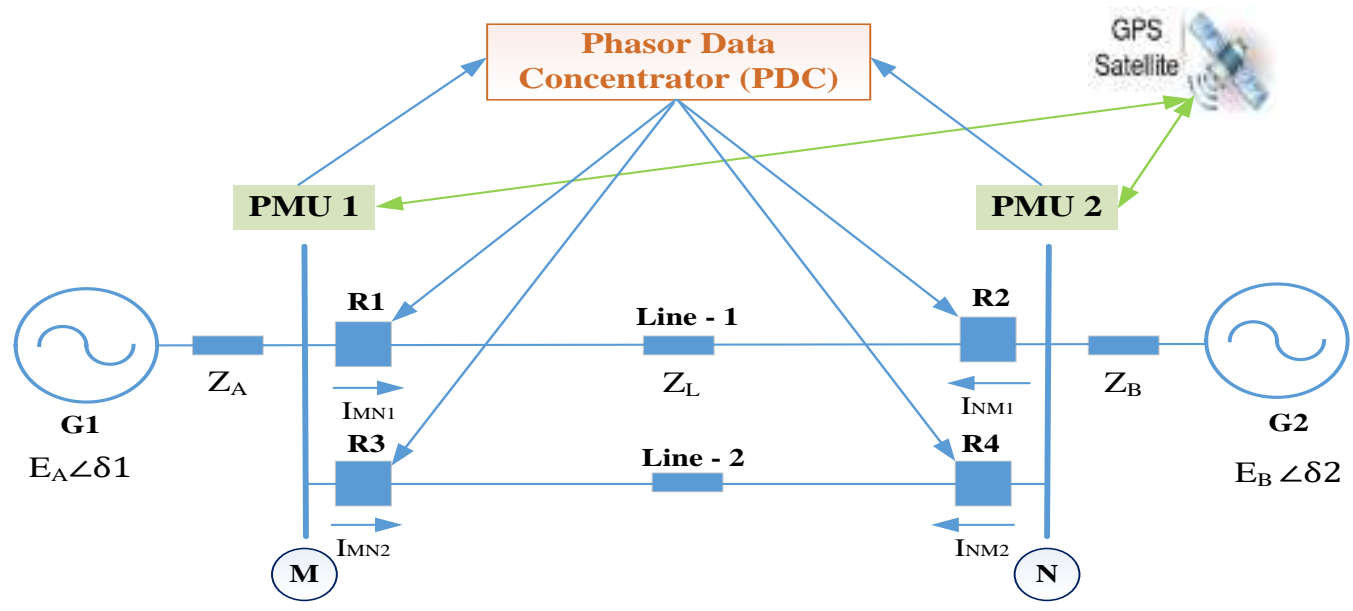

Figure 1. The arrangement of PDC, PMUs and protective relays

\subsection{Methodology of the proposed technique and proposed index}

To locate faults within transmission lines, a technique is introduced in [26] lies on creating an ellipse between the sending, receiving ends voltage difference, and the sending end current. The area of the ellipse, the ellipse's center-to-focus distance and the angle between the ellipse's major axis and the horizontal axis are identified using PMUs to estimate the fault location. Following a similar approach, a novel online technique for dealing with power swing conditions is proposed here using a unique index derived from a constructed locus for the sending and receiving ends current difference and voltage difference. The $(\Delta I-$ $\Delta V)$ ellipse represents the relation between the transmission line's sending and receiving current difference $\left(\Delta I=I_{S}-I_{R}\right)$ on the $\mathrm{x}$-axis and the sending and receiving voltage difference $\left(\Delta V=V_{S}-V_{R}\right)$ on the y-axis. The basic idea of $(\Delta I-\Delta V)$ ellipse is graphically shown in Figure 2. Two mathematical features, the semimajor axis length (a) and the semi-minor axis length (b), define the ellipse.
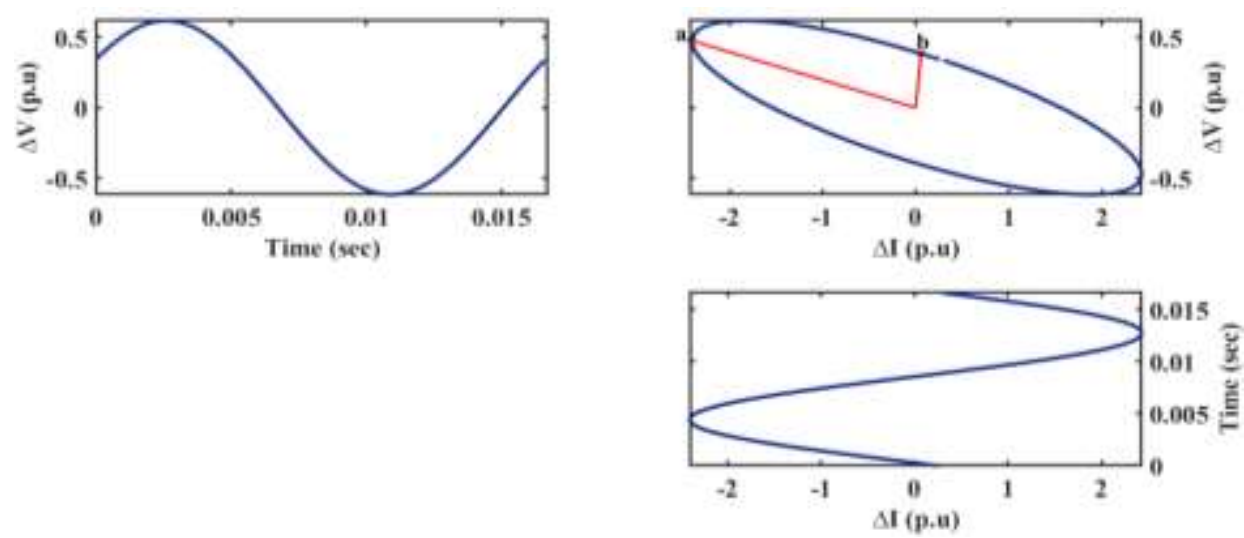

Figure 2. Graphical illustration of the $(\Delta I-\Delta V)$ ellipse

The proposed technique consists of two stages. In the first stage, it uses one index to discriminate between real faults and other conditions. This index is namely ellipse circumference (Cir) which is continuously compared to reference settings $\left(\mathrm{Cir}_{\text {sett }}\right)$. If no fault case is confirmed, the algorithm goes to the second stage where the power angle extracted from PMUs at PDC is used by the distance relay for power swing detection. 
The mathematical equation correlating the current and voltage differences $(\Delta I-\Delta V)$ between the two ends of the protected line is derived from:

$$
\begin{aligned}
& V_{S}(t)=V_{S m} \sin (\omega t+\delta) \& V_{R}(t)=V_{R m} \sin (\omega t) \\
& I_{S}(t)=I_{S m} \sin (\omega t \pm \varphi) \& I_{R}(t)=A I_{S}(t)-C V_{S}(t)
\end{aligned}
$$

Where $V_{S m}, V_{R m}$ are the magnitude of the sending and receiving voltage, $I_{S m}$ is the magnitude of the sending current, $\delta$ is the power angle between the sending and receiving voltage, $\varphi$ is the phase shift between the sending voltage and current while the parameters $A, C$ belong to ABCD parameters of the transmission line.

As discussed in [26], the polar relationship between $\Delta V\left(V_{S}(t)-V_{R}(t)\right)$ and $\Delta I\left(I_{S}(t)-I_{R}(t)\right)$ represents an ellipse [27]. For semi-major axis length (a) and semi-minor axis length (b), as shown in the following equation, the mathematical formula, used to determine the index (Cir) in (p.u) at any sampling instant to be used in the first stage of the proposed scheme, is expressed as follows:

$$
\text { Circumference }(\text { Cir }) \approx \pi\left[3(\mathrm{a}+\mathrm{b})-\sqrt{\left(10 \mathrm{ab}+3\left(\mathrm{a}^{2}+\mathrm{b}^{2}\right)\right)}\right]
$$

\subsection{Steps for implementing the proposed technique}

By using the proposed technique, the distance relay can easily differentiate between actual faults and power swings. Actually, the proposed technique is implemented through two main stages as shown below. The output results for the two stages are incorporated within the ordinary distance relay as displayed in Figure 3.

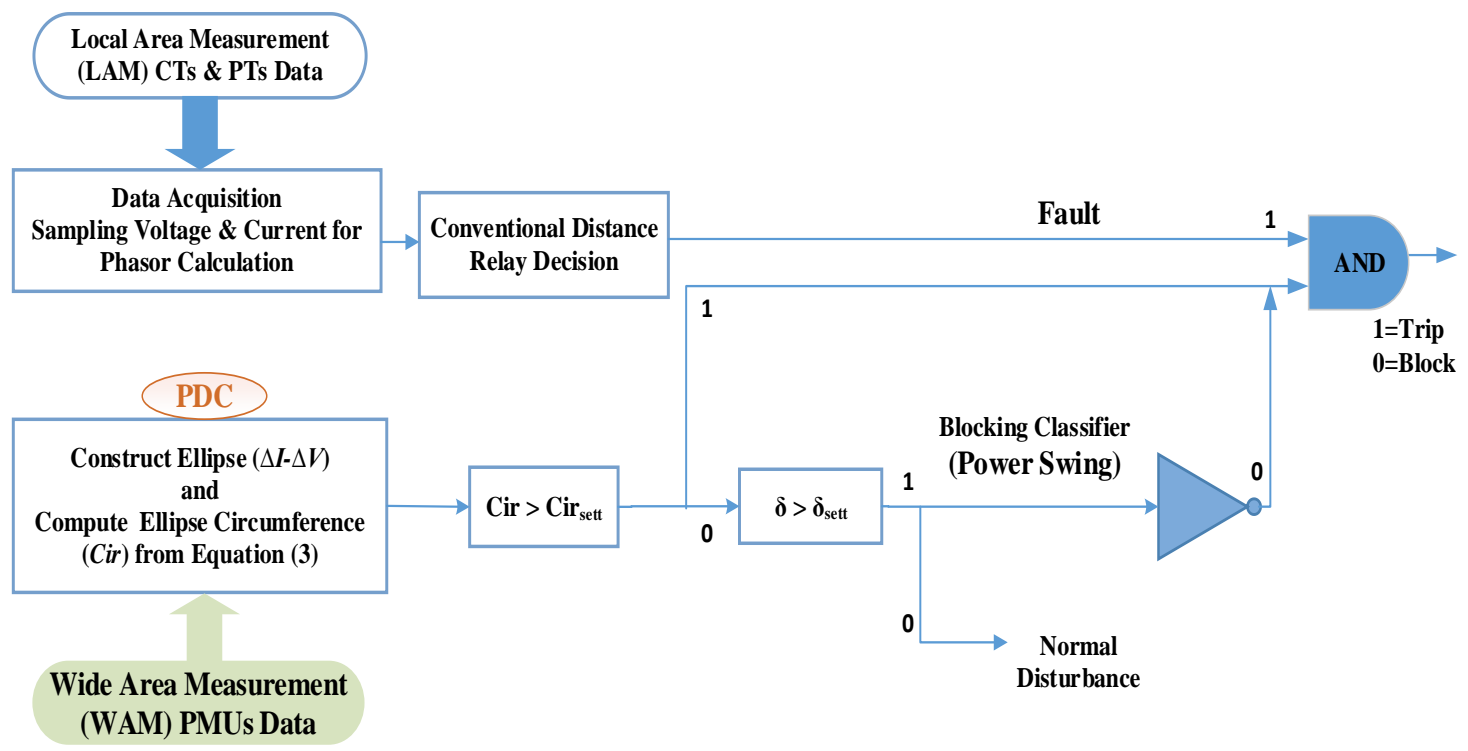

Figure 3. Flow diagram of the proposed technique

\section{$\frac{1^{\text {st }} \text { stage: }}{1)}$}

1)- The instantaneous values for current and voltage differences between sending and receiving ends for each protected line are measured using PMUs.

2)- The synchrophasor measurement data gathered from each area at the PDC is used to construct ( $\Delta I-$ $\Delta V)$ locus.

3)- For every cycle, the geometric features including semi-major axis length (a) and semi-minor axis length (b) are extracted from the ellipse. From these features, the proposed index of ellipse circumference ( $\mathrm{Cir}$ ) is calculated as per (3).

4)- For a real fault condition, the extracted index (Cir) will jump to a higher value larger than the threshold setting $\left(\mathrm{Cir}_{\text {sett }}\right)$. Otherwise, no fault is confirmed, and the technique goes to the second stage to check the power swing probability. 


\section{2nd stage:}

$5)$ - In this second stage, the technique uses the power angle $(\delta)$ to check the power swing phenomenon between the two ends of the protected line. For $\delta>\delta_{\text {sett }}$, a power swing is confirmed, where $\delta_{\text {sett }}$ is the threshold value for $\delta$ to identify power swing in the system. Otherwise, it is considered a normal disturbance.

\section{THE TESTED NETWORK}

A $230 \mathrm{kV}, 60 \mathrm{~Hz}$, a two-area four-machine power system, as shown in Figure 4, is simulated to verify the performance of the proposed technique under different conditions. The system presents ten buses and two areas connected by a weak tie between bus 7 and bus 8 . Each area consists of two coupled units; each unit has the rating of $900 \mathrm{MVA}$ and $20 \mathrm{kV}$. Two loads are connected to the system at buses $7 \& 8$ and also two shunt capacitors are connected to bus 7 and bus 8 . The detailed parameters of the tested network can be found in [28]. The simulation tests are done through power systems computer-aided design MATLAB/SIMULINK software.

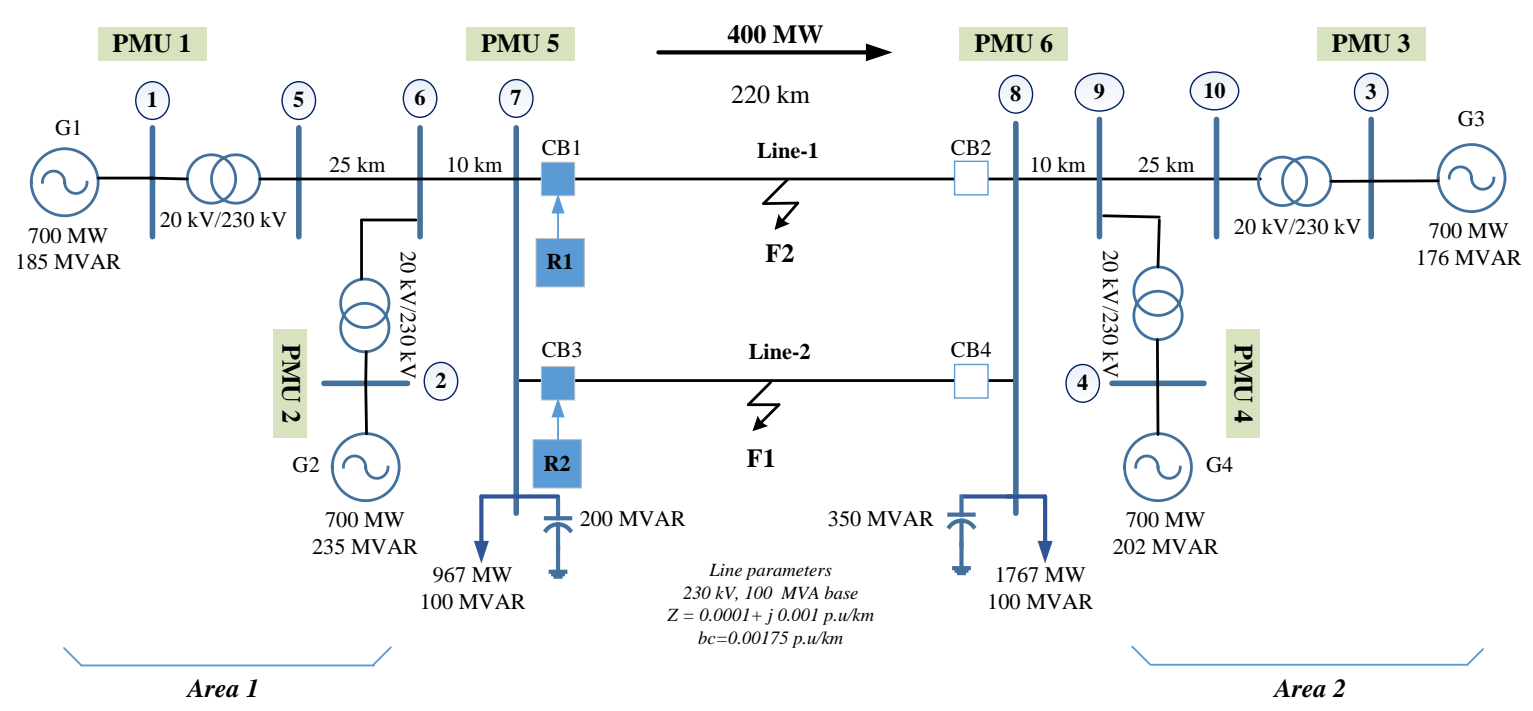

Figure 4. Two-area four-machine power system

\subsection{Placement of PMUs}

For the implementation of the proposed technique, optimal PMUs placement must be taken into consideration in order to achieve observability of faults $[29,30]$. The procedure for PMUs placement in the tested network is achieved as identical to the placement of PMUs implemented in [31] for 9-bus and 39-bus networks. The estimated number of PMUs for the tested network is six PMUs, which are mounted in buses 1 , 2, 3, 4, 7, and 8 to monitor the voltages and currents at each bus. During each cycle, the synchrophasor data is assumed available at the PDC through the communication network.

\subsection{Distance relay setting}

The proposed technique is tested for distance relays R1 and R2 of mho type (which is a voltage controlled directional relay known also as the admittance relay). As shown in Figure 4, R1 and R2 are located at bus 7 at the sending ends to protect Line- 1 and Line- 2 respectively, the Zone- 1 of relays R1 and R2 are set at $80 \%$ of the protected line without any delay time, and Zone- 2 covers up to $120 \%$ of the protected line with 0.25 s delay time. The reach of Zone- 3 is set at $200 \%$ of the protected line such that it can provide backup protection to full length of the protected line with $0.8 \mathrm{~s}$ delay time.

The $\mathrm{Cir}_{\text {sett }}$ should be selected greater than the maximum Cir observed during the fast power swing in addition to further margin to ensure correct detection of faults. Fast power swings with variable frequencies (4-7 Hz) are simulated by creating three-phase faults on Line-2 and isolating them after considerable time. The index Cir $_{\text {sett }}$ is computed for Line-2 using the synchrophasor data of buses 7 and 8 with an additional margin of $40 \%$. For the tested system, the maximum Cir observed during such swing is 35.7 p.u and accordingly the setting is considered as 50 p.u to appropriately distinguish between faults and

An accurate technique for supervising distance relays during power swing (Loai Mohamed Ali El-Sayed) 
power swing. The angle $\delta_{\text {sett }}$ is considered as $30^{\circ}$, which is significantly higher than the maximum angular separation between sending and receiving end buses during steady-state conditions.

\section{RESULTS AND DISCUSSION}

The general practice for applying PSB function in a distance protection scheme is to block all zones during power swings and allow only tripping for fault conditions. To evaluate the performance of the proposed technique, real faults, power swings and faults during power swings either slow or fast will be investigated in the following subsections.

\subsection{Distinguishing real faults and power swing conditions}

Three-phase symmetrical real fault is simulated at Line- 2 and the resulted power swing on Line- 1 is observed. The F1 fault is simulated at $25 \%$ of Line-2 length from the sending end as shown in Figure 4 at $0.5 \mathrm{~s}$ for investigating the trip function at relay R2 (for real faults). Simultaneously, the PSB function at relay R1 is examined after clearing the fault at Line-2. After 6 cycles, the fault is cleared to allow for power swing on the parallel line. The impedance trajectory for the two studied distance relays R1 and R2 is drawn in Figure 5.

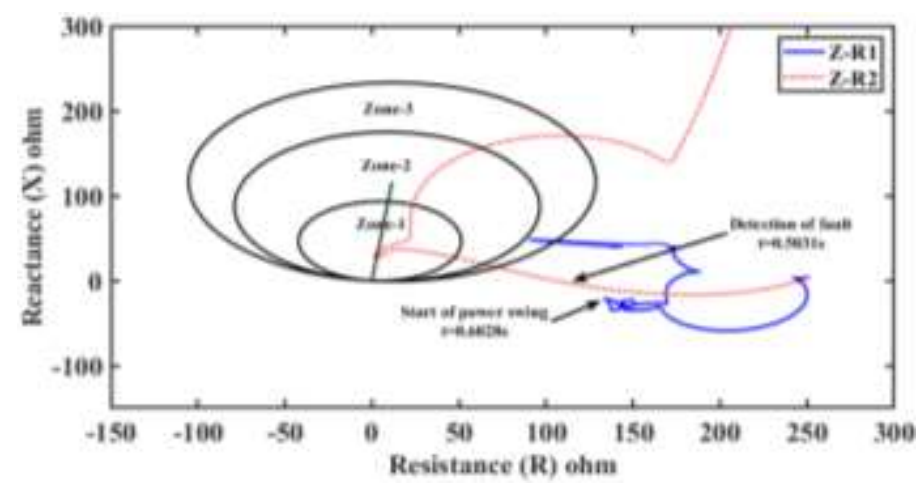

Figure 5. Trajectory impedance for R1 and R2

As revealed in Figure 5, the apparent impedance trajectory of relay R2 (Z-R2) hits Zone-1 boundary and hence Line- 2 should be tripped correctly. After clearing that fault, the impedance trajectory for relay R2 will be located outside the three boundaries, while the impedance trajectory of relay R1 (Z-R1) enters Zone-3 and then gets outs as shown in Figure 5. The distance relay R1 should be able to block tripping during such condition.

The ellipse related to Line-2 during fault (DF) is plotted and compared with the ellipse in normal operation (NO) as shown in Figure 6(a). It ensures that with a 3-phase fault, the circumference of the locus is increased. Figure 6(b) displays the change in ellipse circumference (Cir) for Line-2 as calculated using (3), where the index has already crossed the setting value after fault initiation ensuring a fault occurrence on Line-2. As displayed in Figure 6(c), the trip function for the relay R2 is invoked in less than a quarter cycle after the fault inception and before enters Zone-3 as shown in Figure 5. However, the clearing is intentionally postponed to test the power swing case for R1 as will be shown in the next subsection. The proposed technique has confirmed the results for real faults as in conventional distance relays.

As power swing is likely to occur on Line-1 and it may trip unnecessarily unless it is blocked. The objective of the proposed technique is to appropriately block the trip signal for Line-1 during the power swing. The ellipse related to Line-1 after clearing fault (ACF) is plotted and compared with the ellipse in normal operation (NO) of Line-1 as shown in Figure 7(a). It shows that there is a slight increase in the circumference compared to normal circumference indicating no real fault. The proposed index of ellipse circumference (Cir) for relay R1 is illustrated in Figure 7(b). As shown, there is no significant change in the index and it did not exceed the setting. Thus, the output of stage- 1 of the proposed technique has confirmed that there is no fault on Line-1 as presented in Figure 7(c).

The algorithm proceeds for stage- 2 to check for power swing occurrence. As shown in Figure 7(d), a power swing phenomenon is observed (slip frequency $=0.5 \mathrm{~Hz}$ approx.). In the second stage, the power angle $(\delta)$ between the two ends is compared against the setting value and found to be greater than $\delta_{\text {sett }}$ as revealed in Figure 7(e). 

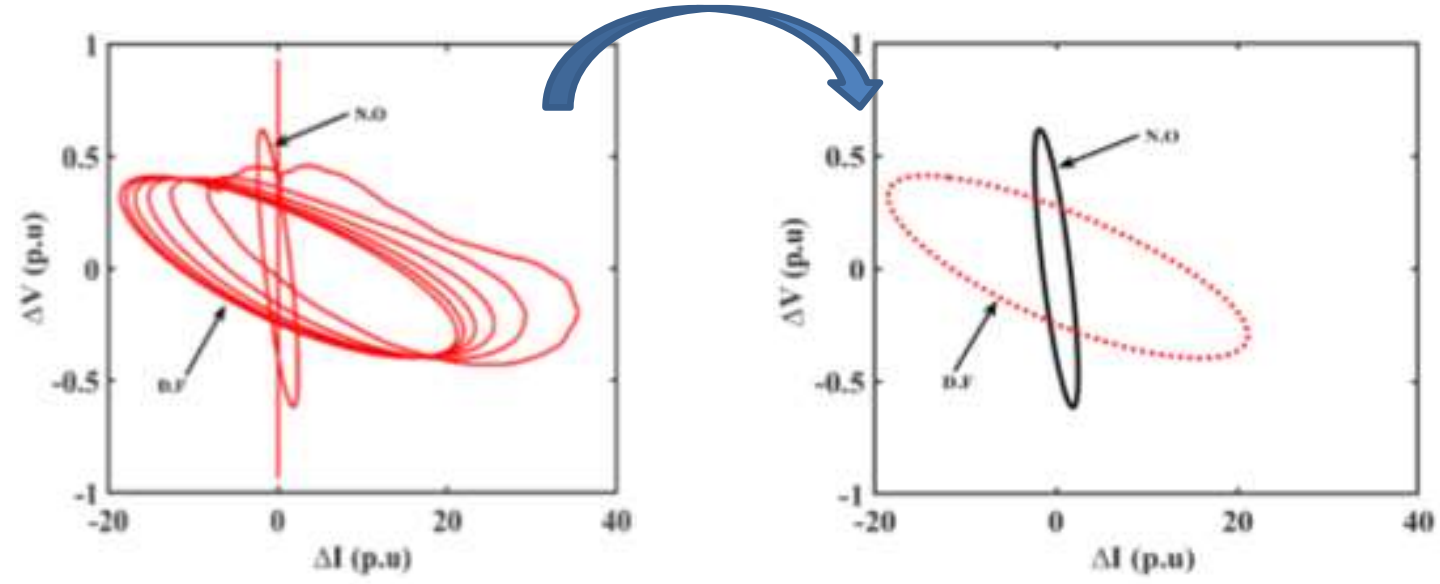

a) Constructed ellipse for Line-2

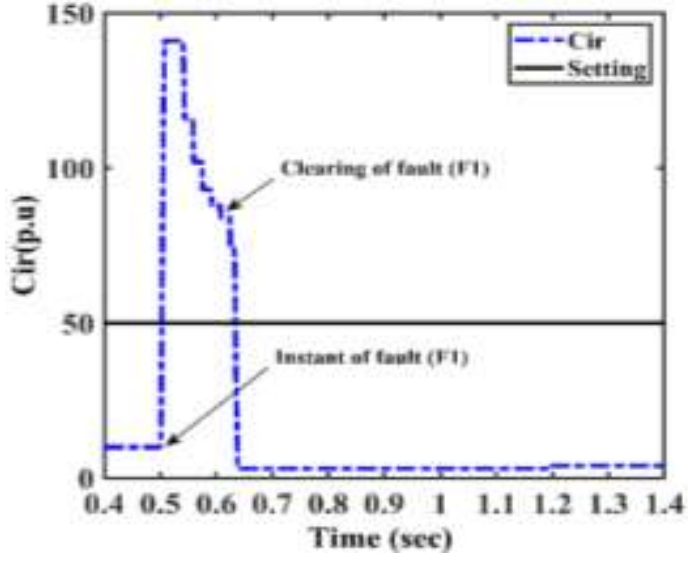

b) Circumference value ( $\mathrm{Cir}$ ) at R2

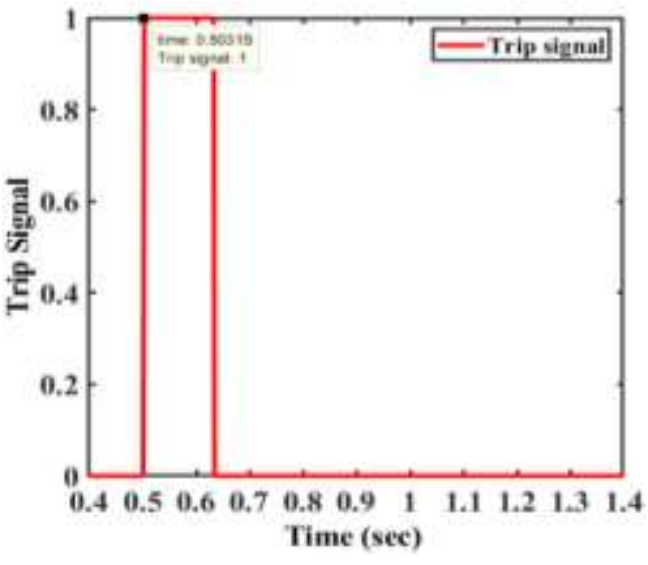

c) The algorithm output (Trip signal for R2)

Figure 6. Performance of R2 for a real fault on Line-2

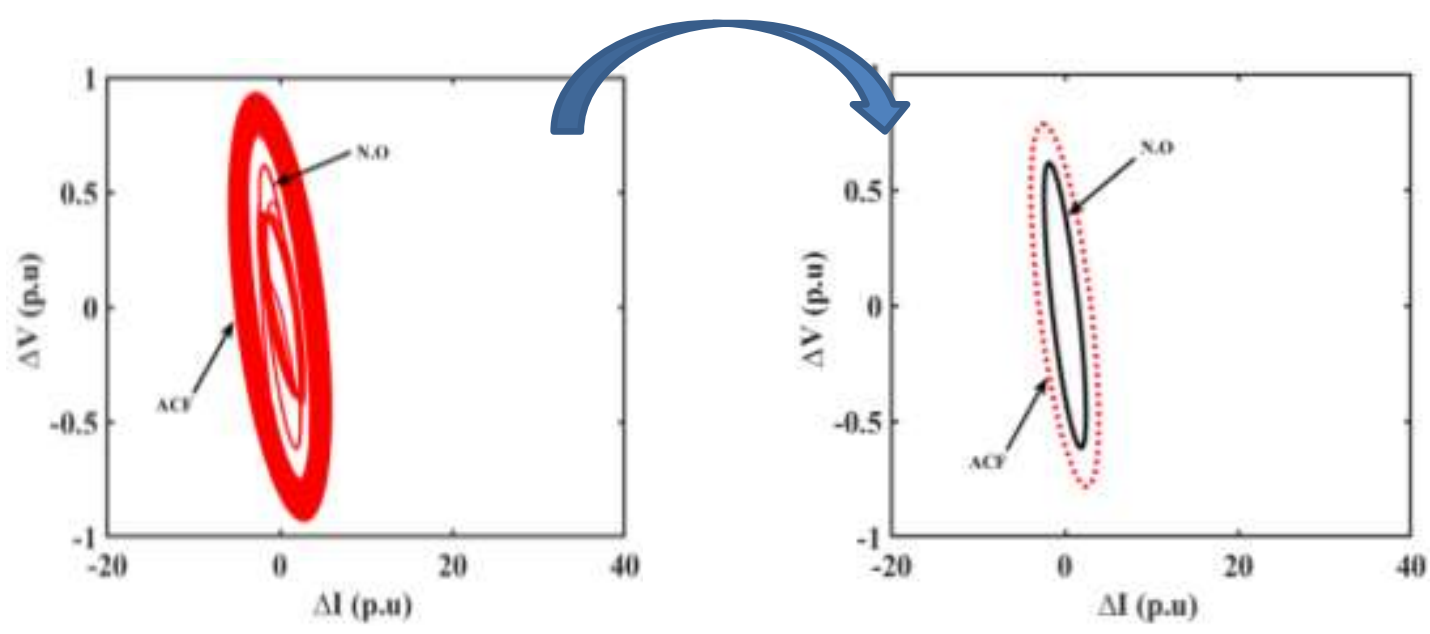

7(a). Constructed ellipse for Line-1 


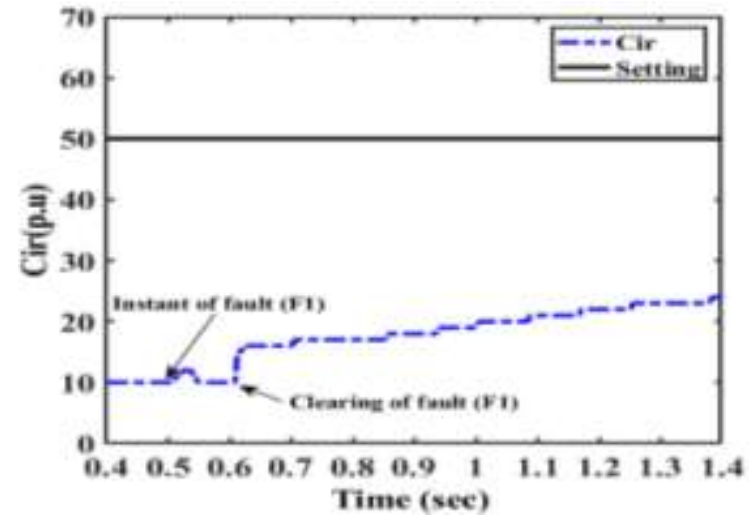

7(b). Circumference value ( $\mathrm{Cir})$ at R1
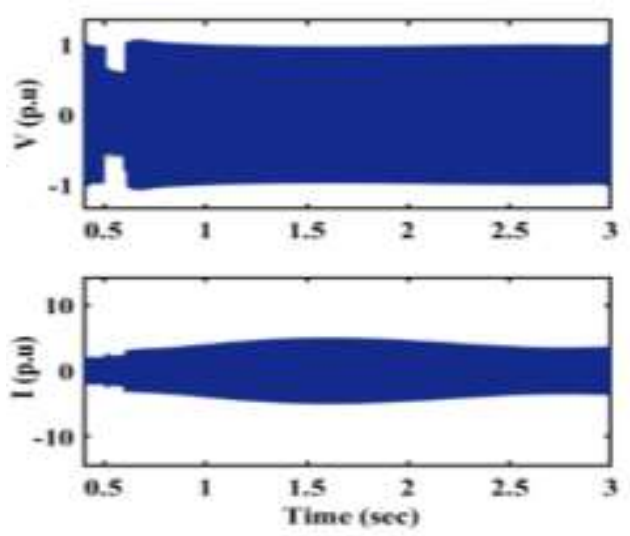

7(d). Voltage and current measured at R1 for phase A

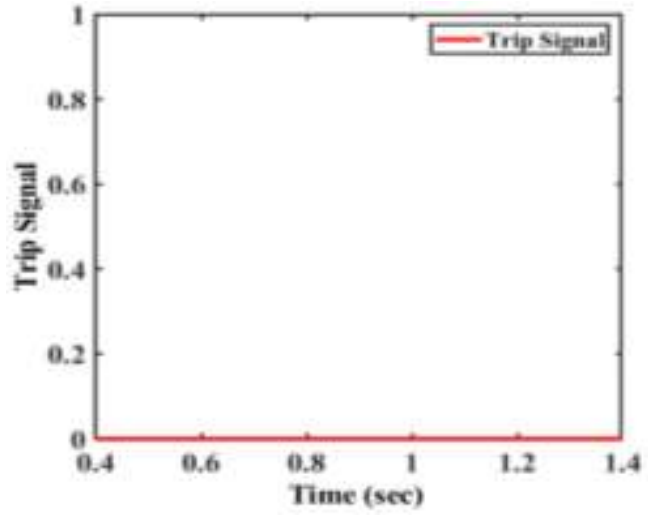

7(c). The algorithm output (Trip signal for R1)

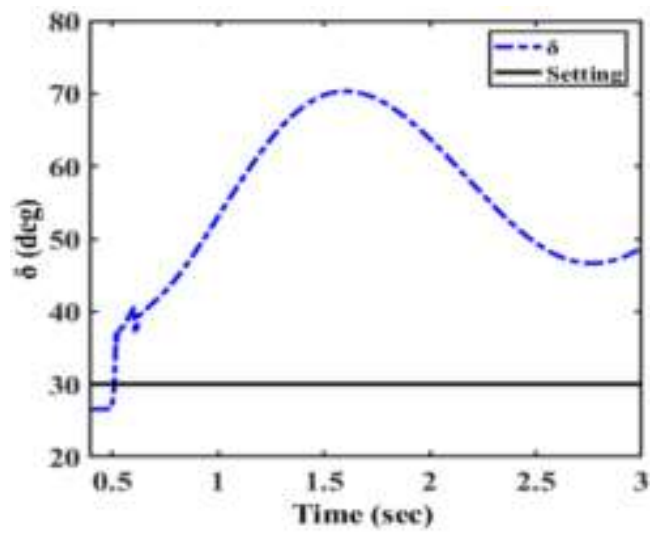

7(e). Power angle between sending \& receiving end

Figure 7. Performance of R1 for a stable power swing on Line-1

\subsection{Detecting faults during power swing}

Due to the symmetric nature of phase voltages and currents during the swing, symmetrical faults are difficult to be discriminated from power swings. To ensure that the distance relay will correctly apply power swing unblocking function and clear any faults during power swing, different symmetrical faults are created during PSB activation. Such faults are simulated at the locations of Zone-1 and Zone-2 regions of distance relay $\mathrm{R} 1$, different fault resistances, fault inception times and slip frequencies either slow and fast power swing conditions. Sample of the achieved results will be demonstrated in the following subsections.

\subsubsection{Detecting faults during slow power swing}

To test the effectiveness of the proposed technique, a solid three-phase fault is applied at $50 \%$ of Line-1 from bus 7 (Zone-1 region of the relay R1) at $4.5 \mathrm{~s}$ during a slow power swing starts after clearing a fault on Line-2 at $1.2 \mathrm{~s}$ as shown in Figure 8(a1). Figure 8(b1) indicates that the ellipse circumference index was below the setting during the power swing and then jumps to a higher value at the inception of the threephase fault occurrence. Accordingly, the proposed technique will unblock the power swing function successfully to ensure that R1 will trip correctly in $4 \mathrm{~ms}$.

To ensure that the proposed technique is not affected by the high fault resistance, the previous simulated fault is repeated with a high fault resistance equals $50 \mathrm{ohms}$. Figure $8(\mathrm{a} 2)$ confirms that the detection of such faults is difficult for common conventional algorithms since there is a very small variation in the measured voltage and current signals after the fault occurs (at $4.5 \mathrm{~s}$ ). However, the proposed technique can detect such fault since the ellipse circumference index jumps to a higher value exceeding the predetermined setting after the inception of a fault as displayed in Figure 8(b2). The trip signal for relay R1 is delayed for about 3 cycles in case of high fault resistance, however, this is still better than the conventional algorithms which cannot detect such faults during power swing. 

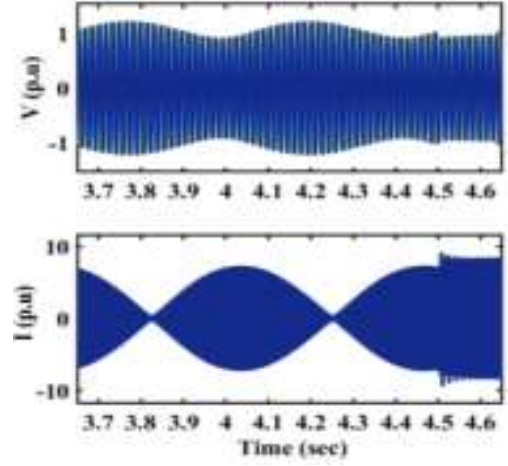

8(a1). During a solid fault
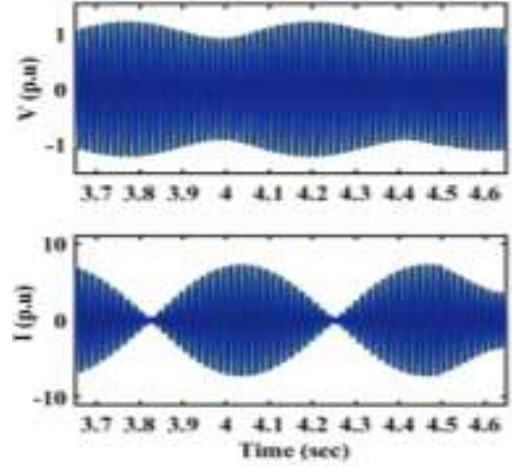

8(a2). During a fault with $50 \mathrm{ohms}$ resistance

8(a). Voltage and current measured at R1 for phase A

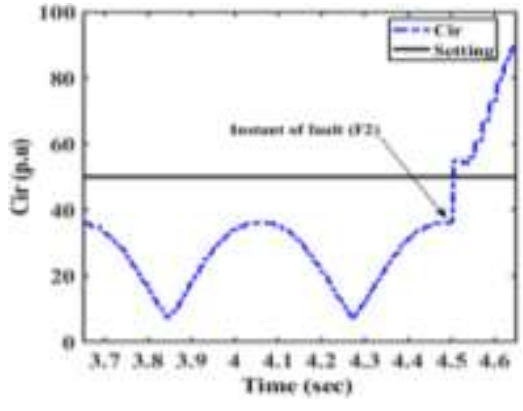

8(b1). During a solid fault

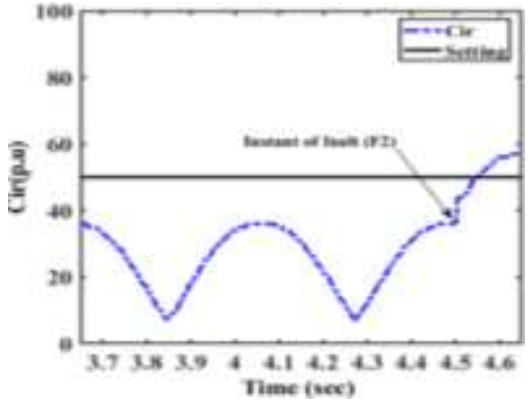

8(b2). During a fault with $50 \mathrm{ohms}$ resistance

b) Circumference value ( $\mathrm{Cir})$ at $\mathrm{R} 1$

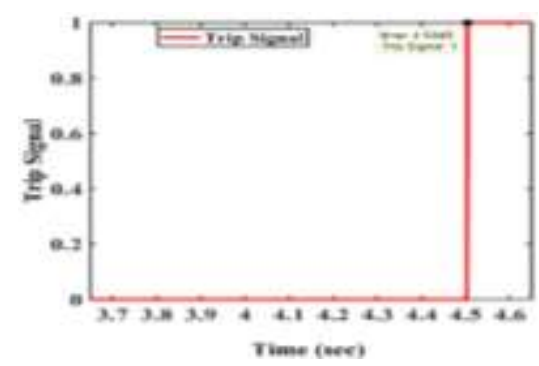

$8(\mathrm{c} 1)$. During a solid fault

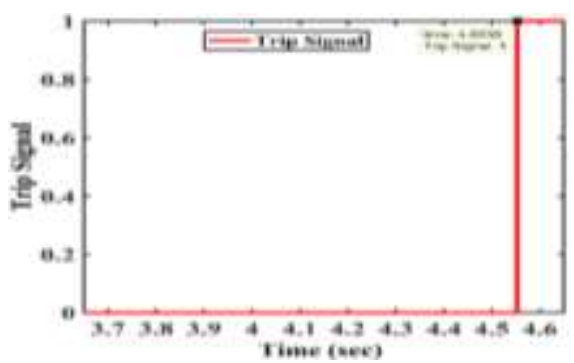

8(c2). During a fault with $50 \mathrm{ohms}$ resistance

8(c). The algorithm output (Trip signal for R1)

Figure 8. Performance of R1 for faults in Zone-1 during slow power swing

\subsubsection{Detecting faults during fast power swing}

A three-phase fault is applied at $90 \%$ of Line-1 from bus 7 (Zone-2 region of the relay R1) at $4.5 \mathrm{~s}$ (at $0^{\circ}$ inception angle) during fast power swing as presented in Figure 9(a1). As expected by the proposed technique, the ellipse circumference index was below the setting during the power swing and jumps to a higher value at the inception of the three-phase fault occurrence and again the proposed technique has succeeded in detecting such fault case as shown in Figure 9(b1). The proposed technique will unblock the power swing function successfully. Consequently, the distance relay R1 will trip for the fault on Line-1 within $1 \mathrm{~ms}$ during such fast power swing.

To further verify the performance of the proposed technique, its performance is also tested during different inception angles. So, the previous fault case is simulated to start at $90^{\circ}$ inception angle, as illustrated by the variation in voltage and current measured at relay R1 shown in Figure 9(a2). According to Figure 
9(b2), the correct performance of the proposed scheme is verified as the ellipse circumference index has jumped to a higher value at fault inception exceeding the setting value. Thus, it can be deduced that by implementing the proposed technique for relay R1, its power swing function is successfully unblocked to ensure that R1 correctly trips just after about $6 \mathrm{~ms}$ from the instant of fault inception.
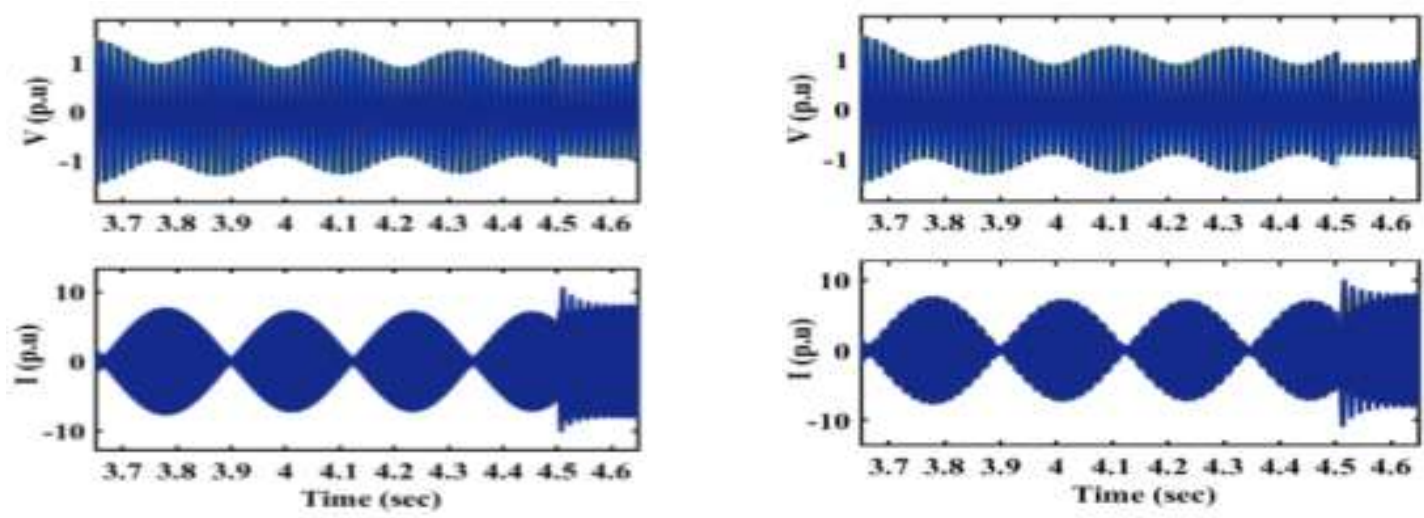

9(a1). During a fault at $0^{\circ}$ inception angle

9(a2). During a fault at $90^{\circ}$ inception angle

9(a). Voltage and current measured at R1 for phase A

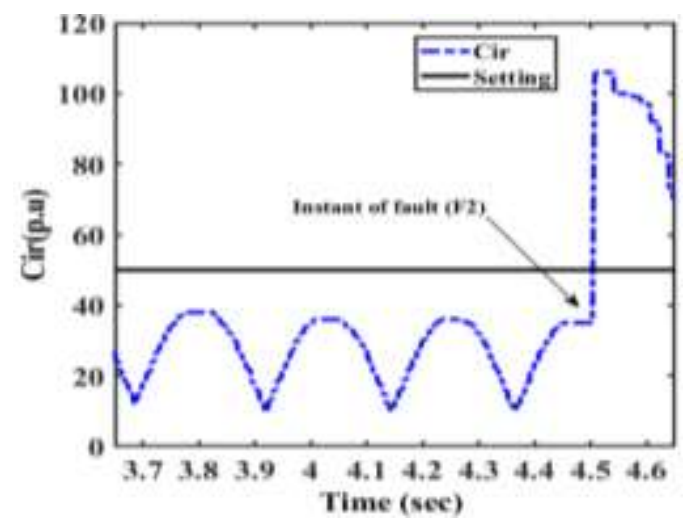

9(b1). During a fault at $0^{\circ}$ inception angle

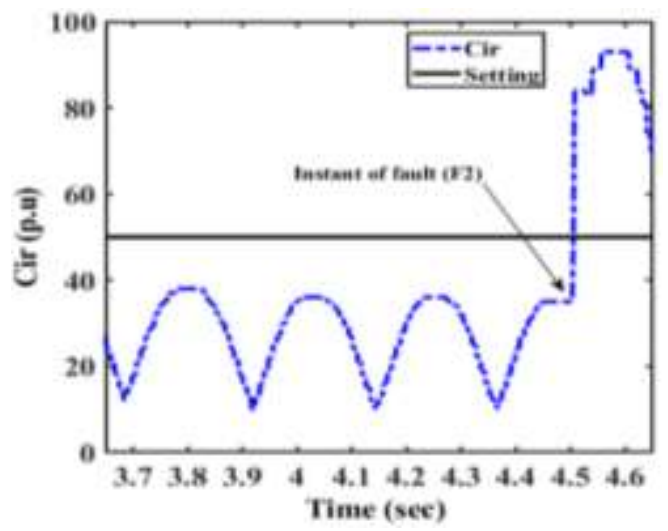

9(b2). During a fault at $90^{\circ}$ inception angle

9(b). Circumference value (Cir) at R1

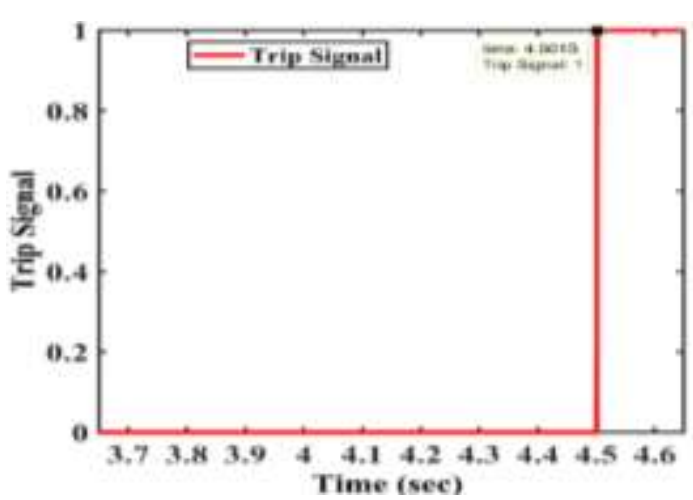

9(c1). During a fault at $0^{\circ}$ inception angle

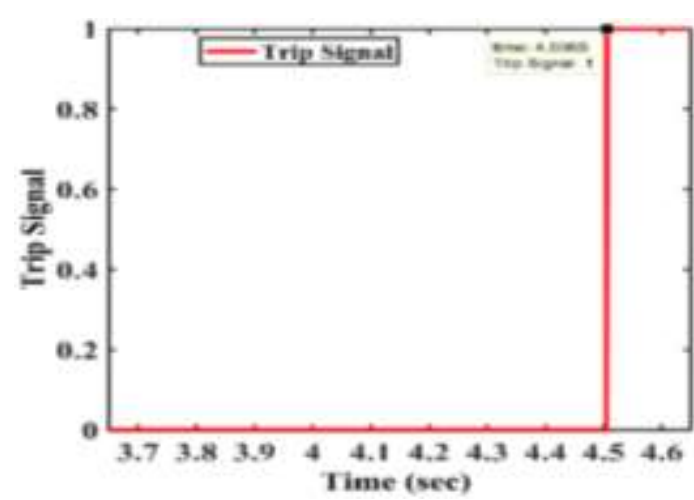

9(c2). During a fault at $90^{\circ}$ inception angle

9(c). The algorithm output (Trip Signal for R1)

Figure 9. Performance of R1 for faults in Zone-2 during fast power swing 


\section{CONCLUSION}

This paper presents a new online technique for supervising the distance relays during power swing in transmission lines based on a $(\Delta I-\Delta V)$ locus diagram, which is considered as a fingerprint of the line. This locus is an ellipse constructed from the sending and receiving current difference on the $\mathrm{x}$-axis and the sending and receiving voltage difference on the y-axis at the PDC using the data gathered from PMUs based on $4 \mathrm{G}$ technology to guarantee high data rates for long distances. For fault discrimination in the first stage, the proposed technique gets benefit from the changes in the circumference of the ellipse, which is strongly correlated to the fault characteristics. In the second stage of the proposed technique, the power angle between the two ends of the protected line is used to check the power swing phenomenon. The performance of the proposed technique is assessed via extensive simulation studies for various swing cases and fault cases by varying the fault location zones, fault resistances, fault inception angles and slip frequencies compared with the normal case to distinguish the geometrical changes of the locus in a unique way. The overall results guarantee the superior efficiency of the proposed technique. Firstly, the proposed technique can correctly distinguish between faults and power swings in real-time. Secondly, accurate and fast detection of symmetrical faults during power swing (within a quarter cycle) is achieved. The results also demonstrate the merits of proposed technique over the existing methods for detecting high fault resistances up to $50 \mathrm{ohms}$ during power swings and ensure a stable performance in blocking and unblocking functioning in the two-area four-machine power system. It should be noted that when high resistance faults greater than $50 \mathrm{ohms}$ are expected in such systems, the operators should reduce the threshold safety margin less than $40 \%$ to enhance the detection sensitivity for such weak faults. In case that the transmission systems are compensated using one of the flexible alternating current transmission systems (FACTS) techniques, significant negative impacts occur that cause the distance relay to mal-operate due to either over-reaching or under-reaching. So, enhancing the proposed technique to be applied in such compensated networks may be considered in future work. Finally, the main features of the proposed technique compared with some conventional methods that can be summarized as follows: (a) Low computational burden and simplicity in implementation, (b) Unnecessary complicated settings, (c) Fast detection of three-phase faults simultaneously with low and fast power swings. (d) Detection of high resistance faults simultaneously with power swings.

\section{REFERENCES}

[1] A. Hamzeh and Z. A. Al-Omari, "Improved model for investigating transient stability in multimachine power systems," Indones. J. Electr. Eng. Comput. Sci. (IJEECS), vol. 13, no. 1, pp. 368-376, 2019, doi: 10.11591/ijeecs.v13.i1.pp368-376.

[2] M. K. Gunasegaran, C. Tan, A. H. A. Bakar, H. Mokhlis, and H. A. Illias, "Progress on power swing blocking schemes and the impact of renewable energy on power swing characteristics: A review," Renew. Sustain. Energy Rev., vol. 52, pp. 280-288, 2015, doi: https://doi.org/10.1016/j.rser.2015.07.066.

[3] A. Esmaeilian and M. Kezunovic, "Impact of electromechanical wave oscillations propagation on protection schemes,” Electr. Power Syst. Res., vol. 138, pp. 85-91, 2016, doi: 10.1016/j.epsr.2016.01.002.

[4] C. Sriram and Y. Kusumalatha, "A review on power swing blocking schemes of distance relay during stable power swings,” Int. J. Eng. Adv. Technol., vol. 8, no. 4, pp. 636-641, 2019.

[5] Y. J. Lee, J. Y. Heo, O. S. Kwon, and C. H. Kim, "A study on an out-of-step detection algorithm using the time variation of complex power: Part I, mathematical modeling," Energies, vol. 13, no. 15, 2020, doi: 10.3390/en13164065.

[6] E. Sorrentino, G. Navas, and E. Orea, "Effect of an additional large disturbance during power swings on the impedance seen by the out-of-step blocking function," Int. J. Electr. Power Energy Syst., vol. 99, no. December 2017, pp. 79-84, 2018, doi: 10.1016/j.ijepes.2017.12.026.

[7] M. M. Ghalesefidi and N. Ghaffarzadeh, "A new phaselet-based method for detecting the power swing in order to prevent the malfunction of distance relays in transmission lines," Energy Syst., 2019, doi: 10.1007/s12667-01900366-8.

[8] A. Capar, E. Unverdi, and A. Basa Arsoy, "Performance Evaluation of Power Swing Blocking in Compensated Transmission Lines," J. Phys. Conf. Ser., vol. 1457, no. 1, 2020, doi: 10.1088/1742-6596/1457/1/012005.

[9] D. Hou, G. Benmouyal, and D. A. Tziouvaras, "Zero-setting power-swing blocking protection," IEE Conf. Publ., no. CP 508, pp. 249-254, 2005, doi: 10.1049/cp:20050047.

[10] B. Taheri, S. Salehimehr, F. Razavi, and M. Parpaei, "Detection of power swing and fault occurring simultaneously with power swing using instantaneous frequency," Energy Syst., vol. 11, no. 2, pp. 491-514, 2020, doi: 10.1007/s12667-018-00320-0.

[11] Y. R. Alsyoufi and A. A. Hajjar, "A high-speed algorithm to discriminate between power swing and faults in distance relays based on a fast wavelet," Electr. Power Syst. Res., vol. 172, no. February, pp. 269-276, 2019, doi: 10.1016/j.epsr.2019.03.021.

[12] N. Z. Mohamad, A. F. Abidin, and I. Musirin, "Detection of fault during power swing in test system interconnected with DG,” Indones. J. Electr. Eng. Comput. Sci., vol. 16, no. 2, pp. 577-585, 2019, doi: 10.11591/ijeecs.v16.i2.pp577-585. 
[13] Azriyenni and M. W. Mustafa, "Application of ANFIS for distance relay protection in transmission line," Int. J. Electr. Comput. Eng. (IJECE), vol. 5, no. 6, pp. 1311-1318, 2015, doi: 10.11591/ijece.v5i6.pp1311-1318.

[14] A. T. So and W. L. Chan, “A Review on Artificial Intelligence Methods," pp. 71-84, 1999, doi: 10.1007/978-14615-5019-8_10.

[15] A. P. Morais, G. C. Júnior, L. Mariotto, and G. Marchesan, “A morphological filtering algorithm for fault detection in transmission lines during power swings," Electr. Power Syst. Res., vol. 122, pp. 10-18, 2015, doi: 10.1016/j.epsr.2014.12.009.

[16] V. Hari, D. S. Kumar, and J. S. Savier, "Phasor Measurement Based Fault Detection and Blocking/De-Blocking of Distance Relay under Power Swing," 2018 Int. CET Conf. Control. Commun. Comput. IC4 2018, pp. 134-139, 2018, doi: 10.1109/CETIC4.2018.8531024.

[17] M. Chougule, G. Gajjar, and S. A. Soman, "PMU Supervised Secure Backup Protection of Distance Relays," Proc. 2019 IEEE PES Innov. Smart Grid Technol. Eur. ISGT-Europe 2019, 2019, doi: 10.1109/ISGTEurope.2019.8905433.

[18] A. Raza, A. Benrabah, T. Alquthami, and M. Akmal, "A review of fault diagnosing methods in power transmission systems," Appl. Sci., vol. 10, no. 4, 2020, doi: 10.3390/app10041312.

[19] M. M. Eissa, "Developing three-dimensional-phase surface-based wide area protection centre in a smart grid with renewable resources," IET Energy Syst. Integr., vol. 1, no. 2, pp. 65-73, 2019, doi: 10.1049/iet-esi.2018.0025.

[20] M. M. Eissa, "Developing wide area phase plane primary protection scheme 'WA4PS' for complex smart grid system," Int. J. Electr. Power Energy Syst,, vol. 99, no. January, pp. 203-213, 2018, doi: 10.1016/j.ijepes.2018.01.002.

[21] A. Ouadi, H. Bentarzi, and M. Chafai, "A New PMU Based Power Swing Detector to Prevent Mal-Operation of Distance Relay 1,” vol. 87, no. 10, pp. 572-578, 2016, doi: 10.3103/S1068371216100059.

[22] V. Hari, D. S. Kumar, and J. S. Savier, "Phasor Measurement Based Fault Detection and Blocking/De-Blocking of Distance Relay Under Power Swing," in 2018 International CET Conference on Control, Communication, and Computing (IC4), 2018, pp. 134-139, doi: 10.1109/CETIC4.2018.8531024.

[23] A. G. Phadke, P. Wall, L. Ding, and V. Terzija, "Improving the performance of power system protection using wide area monitoring systems," J. Mod. Power Syst. Clean Energy, vol. 4, no. 3, pp. 319-331, 2016, doi: 10.1007/s40565-016-0211-x.

[24] J. G. Rao and A. K. Pradhan, "Supervising distance relay during power swing using synchrophasor measurements," IET Gener. Transm. Distrib., vol. 11, no. 17, pp. 4136-4145, 2017, doi: 10.1049/iet-gtd.2016.1110.

[25] M. S. Prabhu, P. K. Nayak, and G. Pradhan, "Detection of three-phase fault during power swing using zero frequency filtering,” Int. Trans. Electr. Energy Syst., vol. 29, no. 1, pp. 1-15, 2019, doi: 10.1002/etep.2700.

[26] A. Abu-Siada and S. Mir, "A new on-line technique to identify fault location within long transmission lines," Eng. Fail. Anal., vol. 105, no. May, pp. 52-64, 2019, doi: 10.1016/j.engfailanal.2019.06.071.

[27] "epdf.pub calculus-and-analytic-geometry-ninth-edition.pdf."

[28] P. Kundur, "[Prabha Kundur] Power System Stability and Control.pdf." p. 1661, 2005.

[29] M. Baba, N. B. M. Nor, T. B. Ibrahim, and M. A. Sheikh, "A comprehensive review for optimal placement of phasor measurement unit for network observability," Indones. J. Electr. Eng. Comput. Sci., vol. 19, no. 1, pp. 301308, 2020, doi: 10.11591/ijeecs.v19.i1.pp. 301-308.

[30] A. P. S. E. George, "Power System Observability and Fault Detection Using Phasor Measurement Units (PMU)," Int. J. Sci. Res., vol. 5, no. 9, pp. 1613-1621, 2016.

[31] M. Eissa and A. Kassem, "Hierarchical Clustering based optimal PMU placement for power system fault observability," Heliyon, vol. 4, no. 8, p. e00725, 2018, doi: 10.1016/j.heliyon.2018.e00725. 